\title{
Hibernoma localizado en el brazo. A propósito de un caso
}

\author{
C. Simón Pérez ${ }^{(1)}$, M.Á. Martín Ferrero ${ }^{(2)}$, J.I. Rodríguez Mateos ${ }^{(3)}$, \\ L. Olmos Molpeceres ${ }^{(4)}$, G. Martínez-García ${ }^{(5)}$
}

Hospital CLÍNICO UNIVERSITARIO DE VALLADOLID

Servicio de TRaumatología Y Cirugía ORTopédica

(1) F.E.A. CIRUGÍA ORTOPÉDICA Y TRAUMATOLOGÍA

(2) JEFE DE SECCIÓN DE LA UNIDAD DE MANO Y NERVIO PERIFÉRICO. PRofesor Titular de TRaUMatología Y CiRUGía ORTOPÉDICA DE LA UNIVERSIDAD DE VALLADOLID

(3) F.E.A. Cirugía PLÁstica y REConStRUCTIVA

(4) Residente DE TRAUMATOLOGÍA Y CIRUGía ORTOPÉDICA

(5) F.E.A. ANATomía Patológica

Correspondencia:

Dra. Clarisa Simón Pérez

Hospital Clínico Universitario de Valladolid

Servicio de Traumatología y Cirugía Ortopédica

Avda. Ramón y Cajal s/n

47005 Valladolid

Teléfono 983420000 ext: 276.

e-mail: simonclarisa@yahoo.es

Los hibernomas son tumores benignos raros, derivados de la grasa parda la cual se observa en el feto y los animales que hibernan. En la mayoría de los casos se presenta como una masa de crecimiento lento y poco dolorosa en las regiones donde persiste este tipo de grasa en el adulto, como la región interescapular, tórax, retroperitoneo, axila e ingle. Describimos un caso de hibernoma en el brazo, localización poco habitual, revisando el diagnóstico y el tratamiento de este tumor cuyo diagnóstico diferencial debe efectuarse con el liposarcoma y con el lipoma intramuscular.

Palabras claves: hibernoma, grasa parda.
Hibernomas are rare benign tumours originating from the brown fat found in the foetus and animals that hibernate. In most cases they present as a slowly growing painfull mass situated in those regions where this type of fat persists in the adults, interscapular regions, thoracic, retroperitoneal regions, axilla and groin. We report a case of hibernoma of the arm, which is an unusual localization, and we revew the diagnostic and therapeutic aspects of this tumors whose main differential diagnosis is liposarcoma and lipoma.

Key words: hibernoma, brown fat.

Rev. Iberam. Cir. Mano - Vol. 36 - Núm. 2 Noviembre 2008 (121-124)

\section{INTRODUCCIÓN}

$\mathrm{E}$ 1 hibernoma es un tumor de partes blandas, poco frecuente y benigno, proveniente de las células de grasa parda ${ }^{1-7}$.

El primer caso fue descrito por Merkel en 1906 que lo denominó «pseudolipoma» ${ }^{8}$. En
1914 Gery acuñó el término de hibernoma porque histológicamente era similar a la grasa parda que tienen los animales que hiber$\operatorname{nan}^{1-4,6,9}$.

El hibernoma es un tumor que suele aparecer en el adulto en las áreas del cuerpo donde persiste la grasa parda como la región interes- 


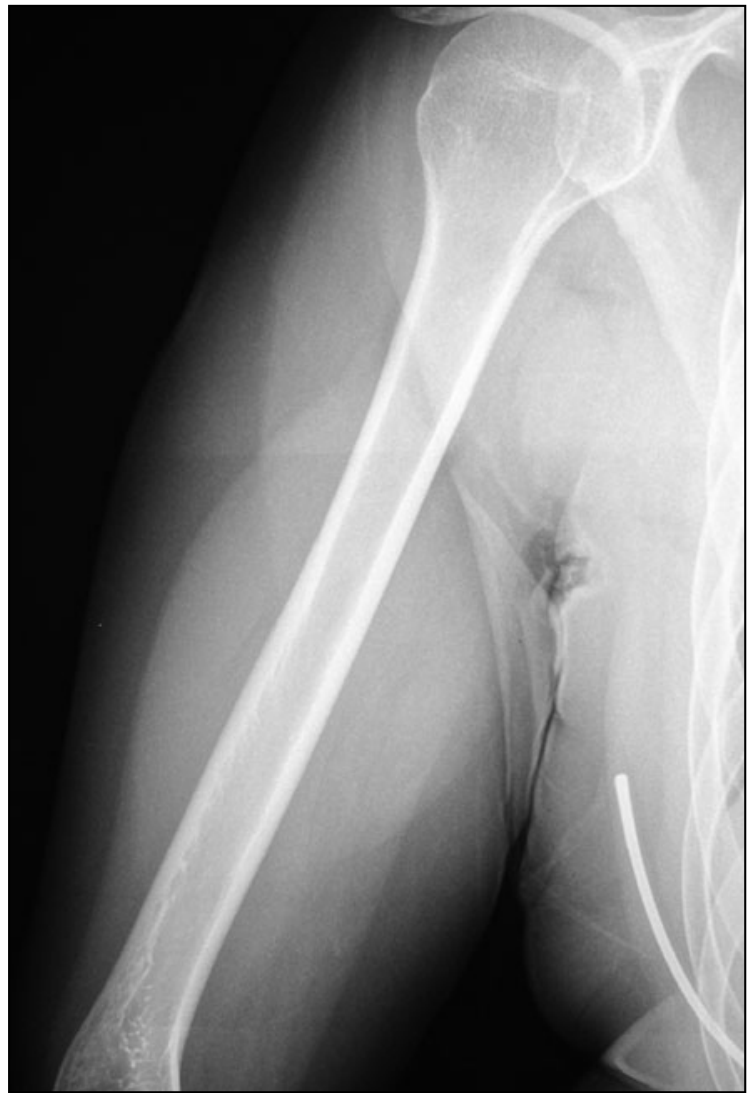

Figura 1. Radiografía simple que muestra una imagen radiolucente.

capular, cuello, axila, tórax, retroperitoneo y la región inguinal ${ }^{1,3-5}$.

El diagnostico es complicado y es frecuente confundirlo con un liposarcoma o un lipoma intramuscular ${ }^{1,2,6,7}$.

Se han observado alteraciones citogenéticas en el hibernoma fundamentalmente traslocaciones y delecciones en el cromosoma 11q132,3,7.

El hibernoma no tiene potencial de malignidad y no recidiva, siempre que se realice una escisión en bloque y completa de la lesión tumoral $^{1,2,4,6}$.

\section{CASO CLÍNICO}

Mujer de 35 años de edad, sin antecedentes de interés, que acudió a consulta por presentar una tumoración a nivel de la cara póstero-interna del brazo derecho que le había aumentado progresivamente de tamaño en los últimos meses, y que no era dolorosa a la palpación. No refería antecedente traumático.

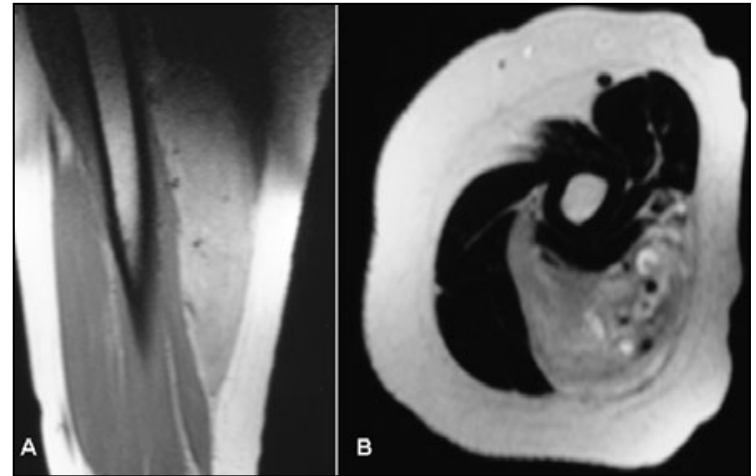

Figura 2. RM en cortes axial (A) y transversal (B) en la que podemos observar la extensión de la masa en ambos planos.

A la exploración general de la paciente se apreciaba un aumento del diámetro del brazo respecto al contra lateral, no se observaban signos inflamatorios; La palpación mostraba la presencia de una masa de un tamaño de $14 \times 8$ $\mathrm{cm}$ en la región póstero-interna del brazo de consistencia duro-elástica, no adherida a planos superficiales pero si a planos profundos. No era dolorosa a la palpación, y no existían alteraciones neurológicas ni vasculares de la extremidad.

En la radiografía simple del brazo no se apreciaban alteraciones óseas significativas salvo la presencia de una imagen con aumento de densidad respecto a la grasa subcutánea (Figura 1). En la RM, en secuencias axial $T 1, T 2$ y STIR y coronal T1 Y T2, se confirmaba la presencia de una formación en el compartimento póstero-interno del brazo, en toda la longitud del caput mediale y caput longum del $\mathrm{m}$. triceps brachii, con ausencia de visualización de fibras y sustituido por una masa mal definida, heterogénea en cuanto a la intensidad de señal, mayormente hiperintensa en todas las secuencias (Figura 2).

En la arteriografía selectiva de la extremidad superior derecha tras punción femoral derecha, se apreciaba en la región del triceps brachii una masa muy vascularizada, con aparente neoformación vascular, que se nutría de un pedículo vascular hipertrofiado del tercio proximal de la arteria humeral, y con venas de drenaje engrosadas, aunque sin evidencia de fístulas arterio-venosas. Las características angiográficas sugerían una neoplasia agresiva, aunque llamaba la atención su escasa agresividad local, 


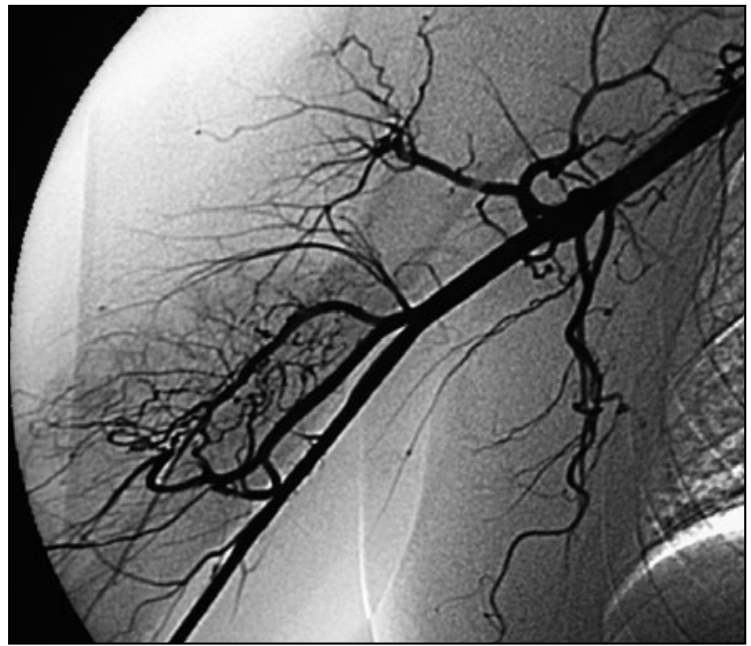

Figura 3: Arteriografía que muestra la gran vascularización de la masa.

ya que respetaba casi completamente las fascias musculares (Figura 3).

La biopsia tumoral fue contraindicada debido a la gran vascularización de la masa tumoral por lo que se decidió la intervención quirúrgica realizándose una exéresis completa, y en bloque, de la lesión, ligando los pedículos vasculares más importantes y respetando las estructuras vasculo-nerviosas de la vecindad (Figura 4).

El análisis anatomo-patológico mostraba una tumoración ovoide irregular de consistencia elástica y superficie lisa con áreas rugosas, parduzcas que al corte presentaban color amarillento y una estructura homogénea laminar, así como una consistencia gomosa. Algunas áreas periféricas próximas al borde presentaban aspecto quístico mucoide. La descripción microscópica mostraba una neoplasia lobular constituida por células adipocitarias con diferentes grados de diferenciación, predominando las de núcleos redondos nucleolados uniformes y citoplasmas granulares acidófilos o microvacuolados. Entre ellos existía un número menor de adipocitos univacuolados maduros. No se observaban mitosis ni áreas de necrosis. Prominente red vascular intratumoral notablemente ramificada. Focos aislados de infiltrado inflamatorio linfoplasmocitario intersticial perivascular (Figura 5).

La evolución postoperatoria de la paciente fue favorable, no existiendo alteraciones vasculares ni neurológicas secundarias a la intervención quirúrgica.

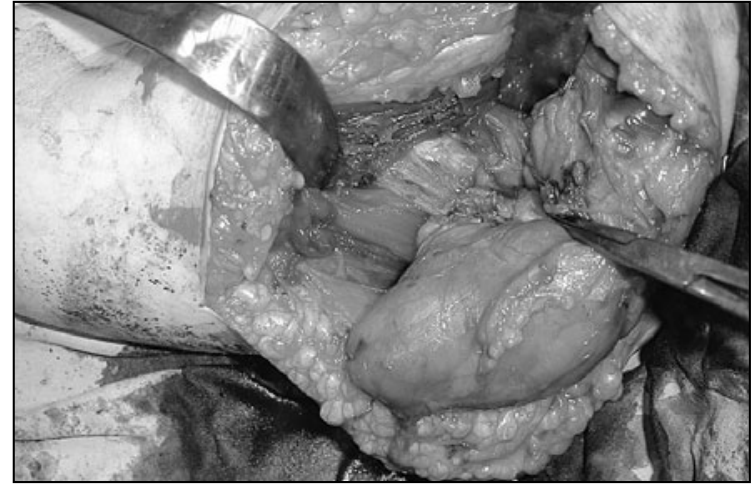

Figura 4: Visión macroscópica del hibernoma.

\section{DISCUSIÓN}

El primer caso de hibernoma fue descrito por Merckel en $1906^{8}$, actualmente existen alrededor de 200 casos descritos en la literatura mundial $^{6}$.

La grasa parda fue descrita en 1670 por $V_{\text {Velsh }}^{2,4}$. En el adulto representa menos del $1 \%$ de la grasa corporal y se halla repartida fundamentalmente a nivel de la región interescapular, cuello, tórax, mediastino, retroperitoneo y en menor nivel en la región axilar e inguinal, siendo localizaciones menos frecuentes las extremidades ${ }^{2,4}$.

Los hibernomas son tumores que aparecen con mayor frecuencia entre los 30-40 años de edad, con ligero predominio femenino ${ }^{1,2,5}$.

Clínicamente se presenta como una masa de crecimiento lento, que debido a su gran vascularización puede presentar calor local y que puede producir sintomatología secundaria a la compresión de estructuras adyacentes ${ }^{1,4,5}$.

Radiológicamente se observa una masa con radiolucencia como si se tratara de una neoplasia lipomatosa que no afecta al hueso. La eco-

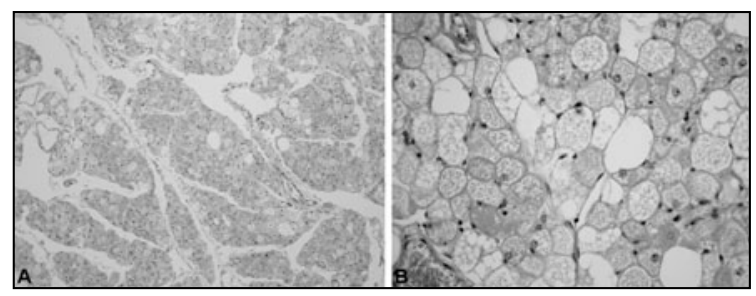

Figura 5: Visión microscópica del hibernoma (hematoxilina-eosina $x$ 20)(A). Visión microscópica del hibernoma (hematoxilina-eosina $x$ 100) (B) constituida por células de hábito adipocitario con diferentes grados de diferenciación. 
grafía muestra una masa uniforme hiperecoica. En la arteriografía se observa una rica vascularización y en ocasiones con fístulas arterio-venosas ${ }^{1,5}$.

La TAC sin contraste se observa una masa de baja atenuación con tabiques, con una estructura interna heterogénea, hiperdensa en comparación con la grasa subcutánea. Después de la administración de contraste intravenoso se realzan los tabiques ${ }^{4,5}$.

En las imágenes de RM se observa, comúnmente, en T1 una señal de intensidad intermedia entre el músculo y la grasa subcutánea, y en T2 como lesiones isointensas con la grasa subcutánea aunque también se han descrito casos de lesiones hipointensas. En las imágenes STIR se observan lesiones hiperintensas la mayor parte de las veces ${ }^{1,4,5}$.

La anatomía patológica del hibernoma está bien documentada, macroscópicamente se describe como una masa blanda gomosa, bien encapsulada aunque infiltra las estructuras adyacentes, especialmente el músculo ${ }^{1,4}$. Microscópicamente los hibernomas se caracterizan por la presencia de células grasas multivacuoladas con pequeños núcleos centrales. Basados en la naturaleza del estroma y en la aparición y prevalencia de células multivacuoladas, se han identificado cuatro variantes histológicas de hibernoma: típico, seudolipoma, mixoide y de células fusiformes, siendo las más frecuentes las dos primeras $1,3,4,7,9,10$.

El diagnostico diferencial de este tumor es complejo y se realiza con tumores benignos como el lipoma, angiolipoma o hemangioma y con tumores malignos como el liposarcoma ${ }^{1,4,5,7}$.

Según algunos autores la biopsia tumoral no está recomendada en los casos que se sospeche un hibernoma debido a la gran vascularización que presenta el tumor ${ }^{5}$. La biopsia estaría indicada cuando no se tenga un diagnóstico de certeza.

El tratamiento definitivo es la escisión completa de la lesión para evitar la recidiva local ${ }^{1,2,4-6}$.

\section{CONCLUSIÓN}

El hibernoma es un raro tumor benigno de la grasa parda. Su localización en el brazo es poco frecuente. Es importante su conocimiento para realizar una diagnostico diferencial con el liposarcoma y con el lipoma intramuscular. $\mathrm{Su}$ tratamiento definitivo es la exéresis completa de la tumoración para evitar recidivas.

\section{BIBLIOGRAFÍA}

1. Alahyane $A$, Bounaim $A$, Jadih A, Janati I-M. Hibernome de l'avant-bras. Chir Main, 2006; 25: 166-8.

2. Essadel A, Bensaid Alaoui S, Mssrouri $R$, et al. L'hibernome: une cause rare d'amaigrissement massif . Ann Chir, 2002; 127: 215-7.

3. Chirieac LR, Dekmezian RP, Ayala AG. Characterization of the mixoid variant of hibernoma. Ann Diagn Pathol, 2006; 10: $104-6$.
4. Lee JC, Gupta A, Saifuddin A, et al. Hibernoma: MRI features in eight consecutive cases. Clin Radiol, 2006; 61:1029-34.

5. Dursun M, Agayev A, Bakir B, et al. CT and MR characteristics of hibernoma: six cases. Clin Imaging, 2008; 32: 42-7.

6. Della Volpe C, Salazard B, Casanova $D$, et al. Hibernoma of the antero-lateral thigh. $\mathrm{Br} \mathrm{J}$ Plast Surg, 2005; 58: 859-61.

7. Turaga K, Silva-Lopez E, Sanger WG, et al. A $(9 ; 11)$ (q34; q13) translocation in a hibernoma. Cancer Genet Cytogen, 2006; 170: 163-6.

8. Merkel H. On a pseudolipoma of the breast. Beitr Pathol Anat, 1906; 39: 152-7.

9. Gery L. Discussions. Bull Mém Soc Anat Paris, 1914; 89:111.

10. Furlong MA, Smith JC, Miettinen $M$. The morphologic spectrum of hibernoma: a clinicopathologic study of 170 cases. Am J Surg Pathol, 2001; 25: 809-14. 